\title{
SOME PROPERTIES OF THE JUNG-KIM-SRIVASTAVA INTEGRAL OPERATOR
}

\author{
A. A. AтtiYA
}

Abstract. The purpose of the present paper is to derive an important inequality of the integral operator $I^{\sigma}(f)$ which was introduced by Jung, Kim and Srivastava. [J. Math. Anal. Appl. 176(1993), 138-147]. Using the technique of differential subordination, an interesting property of $I^{\sigma}(f)$ is also obtained.

Mathematics subject classification (2000): 30C45, 30C80.

Key words and phrases: Analytic functions, univalent functions, convex functions, starlike functions, differential subordination.

\section{REFERENCES}

[1] T. M. FLETT, The dual of inequality of Hardy and Littlewood and some related inequalities, J. Math. Anal. Appl. 38(1972), 746-765.

[2] J. B. JUNG, Y. C. KIM AND H. M. SRIVAstaVA, The Hardy space of analytic functions associated with certain one-parameter families of integral operator, J. Math. Anal. Appl. 176(1993), 138-147.

[3] R. J. LiBera, Some classes of regular univalent functions, Proc. Amer. Math. Soc. 135(1969), 429-449.

[4] J.-L. LIU, A linear operator and strongly starlike functions, J. Math. Soc. Japan. 54(2002), 975-981.

[5] J.-L. LiU, Some applications of certain integral operator, Kyungpook Math. J. 43(2003), 211-219.

[6] S. S. Miller AND P. T. Mocanu, Second order differential inequalities in the complex plane, J. Math. Anal. Appl. 65(1978), 289-305.

[7] S. S. Miller AND P. T. MocAnu, On some classes of first-order differential subordinations, Michigan Math. J. 32(1985), no. 2, 185-195.

[8] S. S. Miller and P. T. Mocanu, Differential Subordinations: Theory and Applications, Series in Pure and Applied Mathematics, No. 225. Marcel Dekker, Inc., New York, 2000.

[9] H. M. SRIVASTAVA AND S. Owa, Current Topics in Analytic Function Theory, World Scientific Publishing Company, Singapore, New Jersey, London and Hong Kong, 1992. 